\title{
Using 'begin robotics' in undergraduate teaching
}

Conference or Workshop Item

Accepted Version

Mitchell, R. J. (2018) Using 'begin robotics' in undergraduate teaching. In: 2018 UKACC 12th International Conference on Control (CONTROL), 5-7 Sep 2018, Sheffield, UK, pp. 444449. Available at http://centaur.reading.ac.uk/80698/

It is advisable to refer to the publisher's version if you intend to cite from the work. See Guidance on citing.

Published version at: https://ieeexplore.ieee.org/document/8516836

All outputs in CentAUR are protected by Intellectual Property Rights law, including copyright law. Copyright and IPR is retained by the creators or other copyright holders. Terms and conditions for use of this material are defined in the End User Agreement. 


\section{CentAUR}

Central Archive at the University of Reading

Reading's research outputs online 


\title{
Using 'Begin Robotics' in Undergraduate Teaching
}

\author{
R.J.Mitchell Senior Member, IEEE
}

\begin{abstract}
Begin Robotics, a successful open online course, introduces cybernetics, robotics, control, haptics, artificial intelligence and artificial life. It was designed as a recruitment tool aimed at Key Stage 3 pupils. However, like previous recruitment methods used by the author, its focus is primarily educational. As such, much of the material is relevant in the first year of the undergraduate degree. This paper discusses the philosophy, how it is used and the associated assessments integrated, and student reaction.
\end{abstract}

\section{INTRODUCTION}

Massive Open Online Courses, or MOOCs, have been offered by many Universities and other institutions since 2008, when the University of Manitoba first offered "Connectivism and Connective Knowledge"[1]. MOOCs cover a large range of topics and run on platforms including edX (Harvard University and MIT), Coursera (Stanford University), and more recently FutureLearn (Open University).

According to Hollands[2], Universities use MOOCs for six reasons: extending reach and access, building and maintaining brand, for economic reasons, improving educational outcomes, innovation in teaching and learning, and conducting research on teaching and learning.

The first MOOC at Reading, Begin Programming, teaches students to write in Java a game on a phone. $10 \%$ of students on our undergraduate courses were influenced to come to Reading by the MOOC, so it is a successful recruitment tool. In addition, it is an example of gamification which is known to be beneficial in encouraging learning[3], especially if it includes an element of 'fun'. As is explained later, the author incorporates Java and Robotics in his courses.

The success of Begin Programming encouraged the author and colleagues to develop another MOOC, this time in the field of Robotics. It was also aimed as a recruitment tool, but educational as well, with some aspects of gamification, and of course 'fun'. It seemed appropriate to call it Begin Robotics.

Begin Robotics builds on both Begin Programing and experience at Reading of robotics as an outreach tool[4]. This outreach was achieved by talks in schools, competitions, the Real Robots magazine series[5] and exhibits in museums. These activities were successful as they did not just explain robotics, but set the context and provided the audience with an opportunity to interact with the robots. The aim was to make robotics interesting and fun, and hence entice students.

Begin Robotics first ran in June 2015, and has run typically twice a year since then. So far almost 50,000 people have enrolled on the MOOC. The educational content of the course however means that it is not just relevant to Key Stage 3 pupils, but also appropriate in the first year of an undergraduate degree as an introduction to robotics and related subjects. As such, students were encouraged to do the MOOC when much of the associated material was taught by a colleague in a series of lectures on robotics. In addition, the author in his module introducing cybernetics and control engineering, used the MOOC to provide some examples of control strategies. In his paper at Control 2016, the author describes the control engineering aspects of Begin Robotics[6] and also the relevant pedagogy used in the design of the course.

As a result of reorganisation at the University, robotics has become part of the Computer Science degree, in a new first year module entitled Applications of Computer Science. In the module, the author introduces artificial intelligence, artificial life, robotics, haptics and virtual reality, some of which is covered in Begin Robotics. As such, part of the author's material is covered in traditional lectures, but the rest is 'flipped' - the students are expected to register on Begin Robotics. This is described here, together with student reaction.

As is noted by Israel[7], there are only a few examples of MOOCs being integrated in educational classrooms at the undergraduate level. Croix and Egerstedt[8] discuss their use of the Control and Mobile Robotics MOOC in their senior course at Georgia Institute of Technology. Other examples are in different fields.

This paper is organised as follows. First the structure of the course is outlined. Then consideration is given on how the new first year module was designed, with a view of using the MOOC. Then is explained how the MOOC was integrated with the course, in terms of delivery and assessment. Finally student feedback is provided and discussed

\section{BEGIN ROBOTICS}

Begin Robotics is a four week course, in which feedback is shown to be key. The course, robotics and the tools used are introduced in week 1 . The second week considers the anatomy of a robot, its sensors, actuators, 'brain' and power supply. The third week covers feedback for control and for interaction between robots and between humans and robots. The final week includes feedback for learning in robotic systems, including artificial intelligence and artificial life. More details can be found on the Futurelearn website[9].

\section{A. Feedback}

Figure 1 depicts the image the author developed, adapted from M C Escher's "Other World" woodcarving, for introducing feedback in a coherent way. It depicts various aspects of robotics from different views. The author has used a similar image in talks to schools, showing cybernetics in a 'different perspective'. 


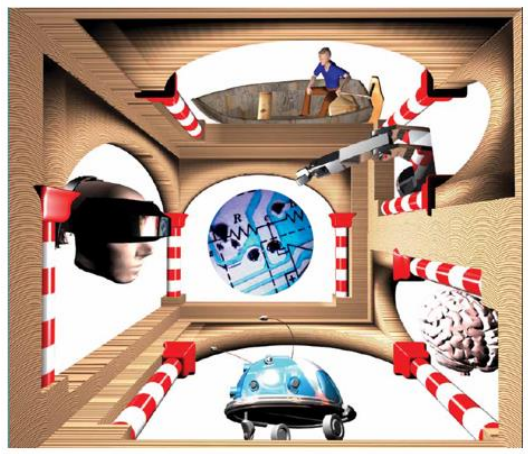

Figure 1 Escher inspired image for introducing robotics

The top arch depicts a steersman (after which cybernetics is named) and is an example of feedback control - other examples such as speed control of a robot are described also. To the right is an arch depicting a manipulator robot. At the bottom is an arch with a mobile robot, in fact the Cybot which featured in 'Real Robots'. The lower arch on the right has a brain, to indicate learning, a feedback process - it is explained that a steersman has to learn how to steer a boat!

As regards interaction, another feedback process, it is noted that the Cybot interacts with its environment and other robots. The image on the left depicts a human wearing VR headset, illustrating human computer interaction.

The image in the centre shows electronics. These, it is explained, are crucial in the operation of robots, facilitating sensor and actuator circuits - it is noted that feedback is often used in such circuits.

The key point here is that robotics is not covered in isolation but is shown to be related to subjects such as control, artificial intelligence and virtual reality. This influenced the teaching of these subjects in the new Computer Science department.

\section{B. Robot for the course}

In [6] the author describes the robots which featured in the Begin Robotics MOOC, including the 'cybot', the 'rover' used in the 'Cyber Challenge'[10] and the Baxter robot.

Most of the interactive sessions, however, use simulations of a mobile robot designed specifically for the course. This is called ERIC, being an acronym for electronics, robotics, intelligence and cybernetics. It is a two wheeled robot, between which are mounted the batteries, motors and the circuit board. The board has on it a wide range of sensors including infrared for object detection, a 3D accelerometer, a microphone, a loudspeaker, motor drivers and speed sensing circuitry. Figure 2 shows a 3D representation of ERIC used in the MOOC, with the wheels, circuit board, motors and battery pack depicted.

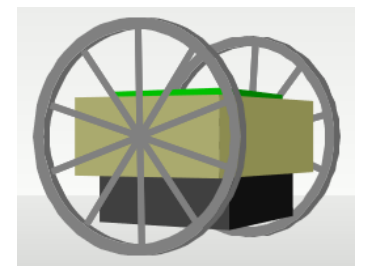

Figure 2 ERIC Robot used in the course
In talks in schools, and in summer schools, participants tried out concepts by programming robots. A simulator with a robot moving round an arena was used, and students wrote functions defining how the velocities of the left and right motors should be set so that the robot achieved a given task, such as exploring the arena and avoiding obstacles. When the robot in the simulator seemed to behave as required, the commands were downloaded onto a real mobile robot.

This concept was adapted for the various exercises done during the MOOC. These involve ERIC, where the participants specify the velocities of each of the wheels under different conditions, such as avoiding obstacles, following a line, steering towards a light or navigating a maze.

ERIC is also used to illustrate various concepts, including speed control and damping the oscillation of the main body of the robot: when ERIC accelerates, the motors, battery pack and circuit board rotate around the axis between its wheels.

\section{Interactive Web Pages for Exercises}

The exercises mentioned above are achieved using the interactive web pages developed by the author for the MOOC. These are written in Javascript, and so, like the course itself, will run on modern browsers operating on smartphones, tablets and computers. More details are in [6].

Typically, an arena is depicted in which one or more ERICs are shown, and the participant specifies the velocity of each motor under different conditions. As an example, one task in week 2 is to command the robot to move around the arena avoiding obstacles using information from two sensors each of which can detect if there is an object within range. The participant enters the velocities as shown in Figure 3 under the associated four different conditions.

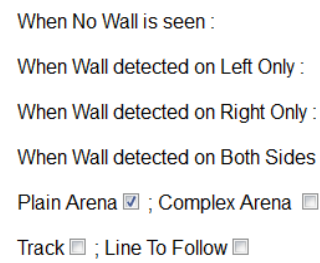

\begin{tabular}{ll} 
Left motor 0 & Right motor 0 \\
Left motor 0 & Right motor 0 \\
Left motor 0 & Right motor 0 \\
Left motor 0 & Right motor 0 \\
Reverse Left Motor $\square$ \\
\hline \multicolumn{2}{|l|}{ Press to Start } \\
\hline
\end{tabular}

Figure 3 Data to enter so ERIC can avoid obstacles

Figure 4 shows part of the web page depicting the robot moving around the arena, avoiding walls and other obstacles.

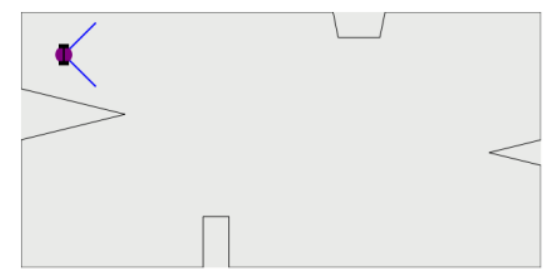

Figure 4 Robot in arena avoiding obstacles

If the user ticks the 'Line To Follow' box, a path is shown on the arena, and the robot has two sensors each of which reports if it can detect a line. The text on the page defining conditions is changed suitably: for instance, 'When Wall detected on Left' is replaced by "When Left Sensor sees line". Figure 5 shows the arena, robot and the line to follow. 


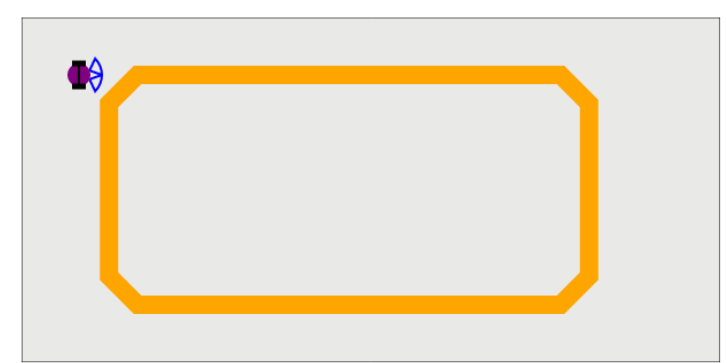

Figure 5 Robot in arena for line following

\section{Interactive Web Pages for illustrating concepts}

These web pages are also used to illustrate particular aspects of the course, such as how range finding sensors work, how accelerometers work (the associated page discusses their use in a mobile phone), how pulse width modulation is used, or how to dampen the oscillations of ERIC's main body.

For instance, Figure 6 illustrates range finding by echo location. The user instigates the emission of a signal from robot $\mathrm{R}$, and the blue arc shows that signal at some point. If the signal encounters an object, a reflection is set up (as shown by the purple arc emanating from object $\mathrm{G}$ ). When any reflection returns to the robot, the time taken is shown. If the robot has two sensors, then the text such as that at the bottom is shown, indicating the time taken for a reflection from each sensor to return to the robot.
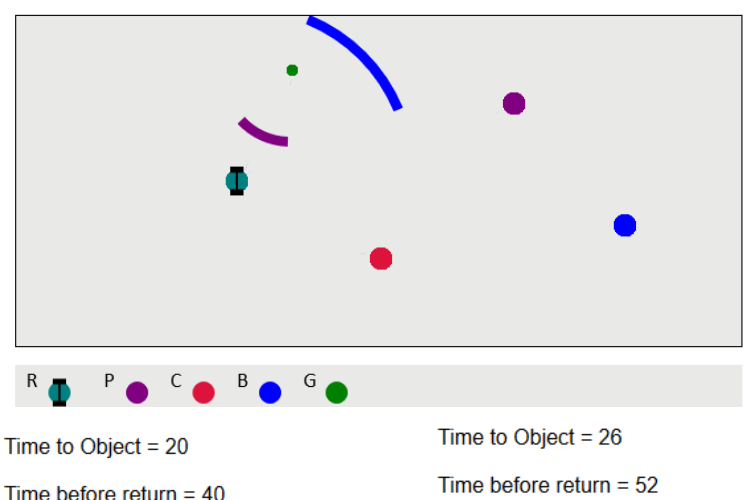

Figure 6 Page illustrating echo location

The author has written many more web pages for illustrating methods taught in other courses, and providing exercises for those other courses, as is described later.

Typically in the MOOC, these web pages are demonstrated in a screencast, produced using Camtasia. These usually start with slides in a powerpoint presentation and then switch to showing the web page in action.

The web pages are very popular, with many positive comments from participants, as is described in [6]. Some school teachers doing the MOOC asked to use them in their schools outside the FutureLearn environment. As such they are published separately on a University web page[11].

\section{FROM CYBERNETICS TO COMPUTER SCIENCE}

When Begin Robotics was designed, the School of Systems Engineering ran degrees in Cybernetics, Electronic Engineering, Robotics and Computer Science. All students did a module which covered the mathematics appropriate to all degrees, and 'Computer Applications' which included artificial intelligence, robotics and communications. The 'engineering' degrees also had modules covering calculus, cybernetics and control engineering. These required A level mathematics or equivalent, Computer Science did not.

The author gave the introductory course on control and illustrated the lectures and ran laboratory practicals which used some interactive web pages. The page on speed control from the MOOC was used in an undergraduate practical reinforcing a demonstration of it in a lecture. In addition, the damping of the oscillatory motion of the ERIC was used in a lecture to illustrate under- and critically- damped systems.

Another colleague gave a five week course on robotics. Its structure was similar to the MOOC, including lectures on robot anatomy (including sensors, actuators), robots for interaction (haptics being that colleague's main research area) and different robot behaviour (including the use of Braitenberg vehicles[12]). It was arranged that the MOOC ran at the same time, and students were encouraged to enrol on it. The lectures and the MOOC covered similar material.

After the University's review of Systems Engineering, the author moved to Computer Science and was instrumental in the redesign of its Computer Science degree. Relevant to this paper, this degree now includes a module called Applications of Computer Science which the author now leads.

The module has four topics, artificial intelligence (AI), computer vision, robotics (with haptics, virtual reality and computer graphics) and data analytics. The author teaches AI and robotics, and the design of those parts of the module was influenced both by the material previously taught and that on the MOOC. From the outset, it was intended that the MOOC would run at the same time as robotics was covered and students would do the MOOC and be assessed on it.

Whilst the MOOC is specifically about robotics, it also covers other topics, including artificial intelligence and haptics. Inherently, robotics also provides examples of artificial life, and of artificial intelligence, such as the use of reinforcement learning in navigating a maze. Robotics also provides a test bed for control.

The existing material on artificial intelligence, however, was much broader than that in the MOOC. Therefore, it was decided that there would remain 10 lectures on AI, some on 'classical' AI including expert systems and problem solving, and some on biologically inspired AI including neural networks, genetic algorithms, and artificial life.

The MOOC includes haptics, incorporating devices such as the Phantom and the Haptic master. The Phantom has a robot 'arm' whose end the user holds. The device makes subtle movements which the user can detect and interpret as feeling textures or small forces. Haptics is often used in virtual reality (VR) allowing the user to 'feel' virtual objects. 
As such it seemed sensible for the module to not only include robotics but also virtual reality (VR), including aspects of computer graphics and audio systems. The link with robotics, however, was maintained.

The graphics lectures cover $4 * 4$ transformation matrices. To demonstrate these, the author developed an interactive web page which allows the scene depicted to comprise four shapes, representing cubes or cylinders. The user specifies the relevant transforms needed to transform each unit size cube or cylinder appropriately. Figure 7 shows a cuboid robot and an ERIC like robot that can be produced.
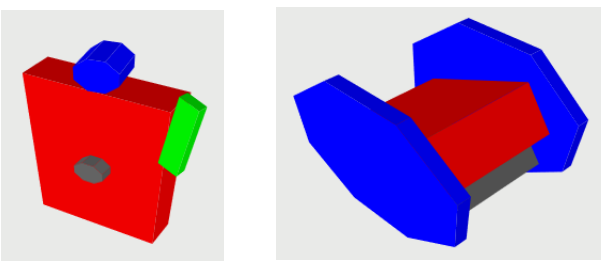

Figure 7 Graphical representations of Robots

For the ERIC, the middle cube represents the motors, and the unit cube is just scaled and rotated. The cylinders for the two wheels need scaling and translating. The cube representing the battery pack under the motors is scaled, translated down and then rotated

Mobile robots are examples of artificial life, but there are others. When describing control systems, the MOOC notes that feedback control can be used to control temperature, say using air conditioning. Here 'rein control' is used in that hot or cold air is blown to heat or cool a room. It is noted that humans (and other animals) also use rein control for regulating body temperature: cooling is achieved by sweating and heating by shivering. This is extended to temperature control of the planet, as per Lovelock's Gaia theory. Lovelock and Watson developed Daisyworld[13] as a way of illustrating this, where the planet has species of black and white daisies, which respectively heat and cool the planet. These are thus examples of artificial life, and are hence in the MOOC. The module includes other examples, including cellular automata and game of life.

It was therefore decided that the robotics and VR part of the module would comprise the MOOC augmented with 5 rather than 10 lectures. Students were expected to register for the MOOC, watch the videos, read the articles and take part in discussions. The other lectures cover aspects of VR, graphics and artificial life. In addition, as control engineering can be a difficult topic to grasp, there is also a lecture reinforcing the concepts of control described in week 3 of the MOOC. This contrasts with the course when the MOOC was first run, robotics was taught by both lectures and the MOOC.

The author teaches Java programming in Year 2 and sets a major coursework using key aspects of object orientation. For 2017, the topic set was to simulate an arena containing different types of robots (a suitable object hierarchy was expected) together with other objects such as obstacles, lights and chargers. It was suggested that students use the MOOC's robot simulations as inspiration for the behaviour and types of robot they programmed.

\section{ASSESSMENT}

The material is readily delivered using standard lectures and the MOOC. However, students need to apply their knowledge and be assessed. Whilst the MOOC has built in exercises, getting marks for them is not straightforward. Also, some of the material to be assessed is not covered in the MOOC.

It was therefore decided to have a standard way of assessing all the relevant material, using Blackboard, the University's Virtual Learning Environment. The AI material is taught in the Autumn term, and during three weeks there are assessments. Similarly, there are assessments for three weeks in the Spring term on the robotics and VR material. In each of these weeks there is a Blackboard quiz, with typically 10 questions. Associated with these questions is a series of interactive web pages, some of which are those used in the MOOC. The student uses each web page to investigate a topic, and then answers one or more questions on the topic.

Miller[14] notes the importance of the educator's presence in a MOOC. To maintain this concept, the quizzes are done in timetabled laboratory sessions, which the author attends, to answer any relevant questions. Students are, however, allowed to do these in their own time, without the support, as long as they submit the quiz by the deadline. This is consistent with taking a MOOC at a convenient time.

Some questions are multiple choice. For instance, in the test associated with commanding the robot, a question (based on one in the MOOC) gives four pairs of motor velocity, and the student answers which one will make the robot turn away from an object on the left.

Some questions require a numerical answer. In the question associated with heuristic search, the 'tile' puzzle is used, where tiles numbered 1 to 8 are in a $3 * 3$ grid, and the user needs to put them in order, by moving the appropriate tile into the gap. To help assess the next move, the Manhattan distance heuristic is used, being the total number of rows and columns all the tiles are away from where they should be.
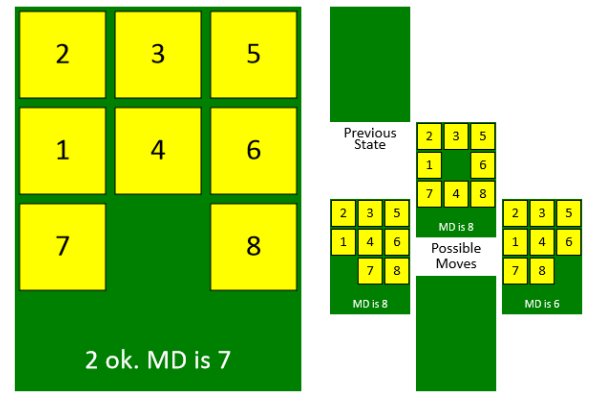

Figure 8 Tile Puzzle web page

Figure 8 shows part of the interactive web page displaying the current state of the puzzle, the number of tiles which are correct, the Manhattan distance, and then also the possible moves that could be chosen, with their Manhattan distance. The user then decides which tile to move and clicks on that tile, and if it is next to the space it moves. Having investigated the page, the student goes to the quiz on the VLE where a different board is shown and the student has to calculate and enter the distance. 
A follow up question is multiple choice as regards which is the next tile to move. For this the student has to first calculate the Manhattan distance of the possible moves.

Similarly, in a test assessing control, the students are shown the image depicted in Figure 9, which is also used in the MOOC. Students are told that the desired speed is 5 and there is no disturbance due to Friction and Weight, and they have to calculate the actual speed.

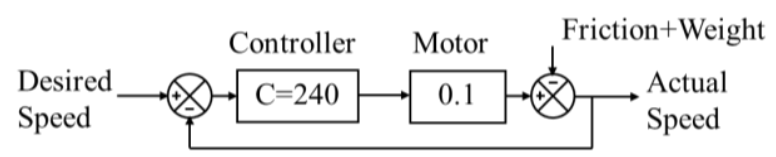

Figure 9 Image in Test On Control

Sometimes multiple answers are required. The next question, for instance, states that the Friction and Weight vary between 3 and -1 , and they have to enter two values, the maximum and minimum speed.

Some questions require strings to be entered. For instance, for the ERIC-like robot in Figure 7, the students enter the transformations needed so that one of the cubes represents the circuit board on top of the motor.

The VLE automatically marks each quiz, and the student is given the score. The quizzes have to be done by a set time, and when that has elapsed, students are provided automatically with feedback on each of their answers. This congratulates them if they are right and gives helpful information if they are wrong. The feedback is delayed until that time as otherwise one student can benefit from the answers of another.

When students have to enter a single numerical value, the question setter can specify a tolerance on the answer. The VLE marks the question as correct if the entered answer is within the acceptable range. For multiple values or for strings, however, the VLE assesses if the answer is correct by matching strings. The questions then have to specify the required format, for instance, that numbers are entered, say, correct to 2 decimal places. This works for those who can follow instructions, but if a student answers 4.8 instead of 4.80 , it is marked wrong.

\section{V.STUDENT FEEDBACK}

In 2017 and 2018, students were asked to fill in a survey on their experience of the MOOC. This comprised one multiple answer question, with a series of statements with which they could agree or disagree, and then two multiple choice questions on how they felt they had learnt and enjoyed having the MOOC. They could then add any other comment.

The results are given below: 12 responded in 2017, 35 in 2018. Table 1 has the response to the series of statements: note an extra question was added in 2018. Tables 2 and 3 give student perception on learning and enjoyability.

\begin{tabular}{|c|c|c|}
\hline Answers & 2017 & 2018 \\
\hline I did not register for the MOOC & $5.9 \%$ & $11.4 \%$ \\
\hline $\begin{array}{l}\text { I would like more modules taught in this } \\
\text { style }\end{array}$ & $41.2 \%$ & $37.1 \%$ \\
\hline $\begin{array}{l}\text { A lecture with the lecturer present is better } \\
\text { as one can ask relevant questions }\end{array}$ & $35.3 \%$ & $57.1 \%$ \\
\hline $\begin{array}{l}\text { It was good being able to write comments } \\
\text { on the MOOC, to get answers from fellow } \\
\text { participants and to be able to answer other } \\
\text { people. }\end{array}$ & $17.6 \%$ & $22.9 \%$ \\
\hline $\begin{array}{l}\text { The lecturer was lazy, giving only } 5 \\
\text { lectures for these topics }\end{array}$ & $0 \%$ & $8.6 \%$ \\
\hline $\begin{array}{l}\text { I liked that the material on the MOOC was } \\
\text { presented in different formats - short } \\
\text { videos and screencasts, articles to read, } \\
\text { interviews to listen to, web pages to view. }\end{array}$ & $70.6 \%$ & $60 \%$ \\
\hline $\begin{array}{l}\text { The interactive web pages helped my } \\
\text { understanding of the topic }\end{array}$ & $76.6 \%$ & $48.6 \%$ \\
\hline $\begin{array}{l}\text { There was too much duplication between } \\
\text { the exercises in the MOOC and those in the } \\
\text { lab sessions }\end{array}$ & $17.6 \%$ & $11.4 \%$ \\
\hline I spent too much time on & $5.9 \%$ & $11.4 \%$ \\
\hline $\begin{array}{l}\text { It was good to be able to do the MOOC at a } \\
\text { time convenient for me }\end{array}$ & $70.9 \%$ & $57.1 \%$ \\
\hline $\begin{array}{l}\text { I learnt more from the MOOC than from } \\
\text { the normal lectures }\end{array}$ & $5.9 \%$ & $20 \%$ \\
\hline $\begin{array}{l}\text { The MOOC, lectures and practicals were } \\
\text { well organised }\end{array}$ & $70.6 \%$ & $45.7 \%$ \\
\hline $\begin{array}{l}\text { I think it a good idea to have some of the } \\
\text { module taught by the MOOC, but there } \\
\text { was too much material to be delivered }\end{array}$ & $5.9 \%$ & $25.7 \%$ \\
\hline $\begin{array}{l}\text { The lecture covering control was necessary } \\
\text { to help the understanding of the more } \\
\text { mathematical parts of the MOOC }\end{array}$ & $35.3 \%$ & $22.9 \%$ \\
\hline $\begin{array}{l}\text { It was good that the MOOC's participants } \\
\text { included both Reading students and people } \\
\text { from round the world. }\end{array}$ & $\mathrm{n} / \mathrm{a}$ & $31.4 \%$ \\
\hline
\end{tabular}

\section{Table 1 General comments}

There are various messages coming from this. The students like the material being delivered in different formats. External participants of the MOOC agree with this.

Students say they prefer a lecturer present, but like to be able to study at a time convenient to them. This is consistent with the findings of Firmin et al[15] and Caulfield et al[16]. They felt they learnt more from the MOOC than the lectures, and enjoyed the MOOC more. The author was concerned that there may have been too much material: students disagreed. 


\begin{tabular}{|l||r|r||}
\hline & $\mathbf{2 0 1 7}$ & $\mathbf{2 0 1 8}$ \\
\hline \hline I learnt much more from the MOOC & $5.9 \%$ & $9.4 \%$ \\
\hline \hline \begin{tabular}{l|l} 
I learnt a little more from the MOOC \\
\hline \hline $\begin{array}{l}\text { I learnt about the same from the MOOC } \\
\text { as lectures/labs }\end{array}$
\end{tabular} & $23.5 \%$ & $34.4 \%$ \\
\hline \hline $\begin{array}{l}\text { I learnt a little more from the lectures/labs } \\
\text { than the MOOC }\end{array}$ & $23.5 \%$ & $21.9 \%$ \\
\hline \hline \begin{tabular}{l} 
I learnt much from the lectures/labs \\
\hline \hline Not Applicable
\end{tabular} & $11.8 \%$ & $6.3 \%$ \\
\hline \hline
\end{tabular}

Table 2 Student perception on Learning

\begin{tabular}{|l|r|r||}
\hline & $\mathbf{2 0 1 7}$ & $\mathbf{2 0 1 8}$ \\
\hline \hline $\begin{array}{l}\text { I enjoyed the MOOC much more than the } \\
\text { lectures/labs }\end{array}$ & $5.9 \%$ & $9.4 \%$ \\
\hline \hline I enjoyed the MOOC a little more & $23.5 \%$ & $28.1 \%$ \\
\hline \hline I enjoyed the MOOC about as much as & $41.2 \%$ & $28.1 \%$ \\
\hline \hline I enjoyed the lectures/labs a little more & $17.6 \%$ & $18.8 \%$ \\
\hline \hline I enjoyed the lectures/labs much more & $5.9 \%$ & $6.3 \%$ \\
\hline \hline Not Applicable & $5.9 \%$ & $9.4 \%$ \\
\hline
\end{tabular}

Table 3 Student Perception on Enjoyability

The free text comments included useful information. "The MOOC felt like a good addition to the course and was very useful, however, I feel as though the lectures are more to the point and therefore more useful for understanding the material of the course." This was not surprising as the MOOC was aimed as a general introduction to the subject, at Key Stage 3. A related comment was: "I think having the MOOC was a very good idea and was very useful for the course but I feel that having more of the critical aspects of the MOOC being covered in lectures as well would be useful as opposed to having half the number of lectures per week."

Another comment was: "I would say that, in short term, I learned about the same amount of information in the MOOC and the lectures. However, when it comes to revising, I find it easier to go back to the information, videos, and practicals in the MOOC, than rereading lecture notes, so in long term, I would say that the MOOC is better for going over information again."

Israel[7] says that using MOOCs does not have a significant detrimental effect on student attainment. In the 2017 exam, however, students did worse on the robotics question than the AI questions. This might have been because the question include PWM control of motors which was only described in the MOOC and not highlighted, for instance, in one of the assessments. This has been addressed in 2018, but the author will monitor this aspect. Before the reorganisation, students from different degrees took Robotics, so comparisons with then are probably not relevant.

\section{CONCLUSION}

Begin Robotics is a popular MOOC, which has now been successfully incorporated in the teaching of an undergraduate module. In particular, an appropriate assessment strategy has been utilised which is consistent with the rest of the module. Students are generally supportive of the use of the MOOC, and feel they enjoy the material taught there more.

\section{REFERENCES}

[1] Tharindu R. Liyanagunawardena, Andrew A. Adams, and Shirley A Williams. "MOOCs: A Systematic Study of the Published Literature 2008-2012." International Review of Research in Open and Distance Learning 14, 2013, 201-27

[2] F.M. Hollands (2014). Why do institutions offer MOOCs? Journal of Asynchronous Learning Network, 18(3). doi:10.24059/olj.v18i3.464

[3] M. Leaning (2015). A study of the use of games and gamification to enhance student engagement, experience and achievement on a theorybased course of an undergraduate media degree. Journal of Media Practice, 16(2), 155-170.

[4] R.J. Mitchell, K. Warwick, W. Browne, M. Gasson and J. Wyatt, 'Engaging Robots: Innovative Outreach for Attracting Cybernetics Student, IEEE Transactions on Education, Volume: 53, Issue: 1; 2010, Digital Object Identifier: 10.1109/TE.2009.2024932

[5] J. E. A. Wyatt, "A study of perceptions of robots through the development of a mass market consumer robotic product," Ph.D. dissertation, University of Reading, Reading, U.K., 2006.

[6] R.J.Mitchell, Introducing control in an open online course, Proc Control 2016, Belfast, Sep 2016, DOI: 10.1109/CONTROL.2016.7737601

[7] Maria Joseph Israel, Effectiveness of Integrating MOOCs in Traditional Classrooms for Undergraduate Students, September 2015 International Review of Research in Open and Distance Learning 16(5):102-118, DOI10.19173/irrodl.v16i5.2222

[8] J.-P. de la Croix, and M. Egerstedt, "Flipping the controls clasroom around a MOOC," in Proc. ACC Annu. Conf., Jun 2014..

[9] https://www.futurelearn.com/courses/begin-robotics

[10] P. Minchinton, S. Gould and R. Mitchell, "The cyber challenge: a robotics project to enthuse". 10th IFAC Symposium Advances in Control Education, IFAC Proc Vol 46, Issue 17, 2013, Pages 168-173.

[11] R J Mitchell https://www.reading.ac.uk/UnivRead/vr/OpenOnline Courses/Files/Simulation2/BeginRoboticsSimulationindex2.pdf 2015.

[12] V. Braitenberg. Vehicles: Experiments in synthetic psychology. Cambridge, MA: MIT Press, 1984.

[13] A.J Watson and J. E. Lovelock (1983), Biological homeostasis of the global environment, The parable of Daisyworld, Tellus, Ser. B, 35, 284 289.

[14] Sandra L. Miller, "Teaching an Online Pedagogy MOOC, MERLOT" Journal of Online Learning and Teaching, Vol. 11, No. 1, March 2015

[15] R. Firmin, E. Schiorring, J. Whitmer, T. Willett, E.D Collins and S. Sujitparapitaya. (2014). Case study: Using MOOCs for conventional college coursework. Distance Education, 35 (2), 178-201. doi: 10.1080/01587919.2014.917707

[16] M. Caulfield, A. Collier and S. Halawa (2013, October 7). Rethinking online community in MOOCs used for blended learning [Web log post]. Retrieved from http://www.educause.edu/ero/article/rethinking-onlinecommunity-moocs-used-blended-learning 